\title{
Care of the Patient With Cirrhosis
}

\author{
Anitha Yadav, M.D., and Hugo E. Vargas, M.D.
}

Caring for patients with cirrhosis involves multidisciplinary and timely management of several complications while the patients are awaiting liver transplantation (LT). Prompt identification and treatment of complications can potentially improve survival and quality of life for this patient population. For practical purposes, in this review we focus on the complications of cirrhosis that are common to all causes of end-stage liver disease, underscoring issues that are important in some of those subpopulations.

\section{Portal Hypertension}

Portal hypertension (PTH) refers to the complex hemodynamic adjustment that occurs as the liver deals with increasing fibrosis and the subsequent increase in resistance to flow in the hepatic sinusoids. The pathophysiology of PTH includes splanchnic vasodilation, increase in the activation of the renin-angiotensin-aldosterone axis, and compensatory cardiovascular adjustments that help to increase hepatic sinusoid flow but lead to a constellation of complications that can threaten the survival of a patient with cirrhosis. $^{1}$

\section{Ascites}

Ascites is one of the most common complications of cirrhosis. Once ascites develops, the probability of survival at 5 years is only $44 \%{ }^{2}$ All patients with new-onset ascites should undergo a diagnostic paracentesis. A serum-ascitesalbumin gradient $\geq 1.1 \mathrm{~g} / \mathrm{dL}$ is diagnostic of PTH-related ascites. Ascitic fluid cell count and differential, ascitic fluid protein, and, if infection is suspected, ascitic fluid cultures should also be obtained. All hospitalized patients with ascites should also undergo paracentesis to prevent mortality from spontaneous bacterial peritonitis. ${ }^{3}$

Management of ascites involves dietary education and medical therapy (Fig. 1). Diuretics are the mainstay of therapy and should be discontinued in patients with renal dysfunction (serum creatinine $>2.0 \mathrm{mg} / \mathrm{dL}$ ), hyponatremia (serum sodium $<120 \mathrm{mmol} / \mathrm{L}$ ), and worsening hepatic encephalopathy. ${ }^{3}$ Less than $10 \%$ of patients with cirrhosis fail to respond to standard medical therapy and develop refractory ascites (Fig. 1). Patients who undergo large volume paracentesis for refractory ascites should receive albumin infusion ( $8 \mathrm{~g} / \mathrm{L}$ of fluid removed) to reduce circulatory dysfunction and improve survival. ${ }^{4}$

\section{Spontaneous Bacterial Peritonitis}

Spontaneous bacterial peritonitis (SBP) is diagnosed when the ascitic fluid absolute polymorphonuclear leukocyte count is $\geq 250$ cells $/ \mathrm{mm}^{3}$. Diagnostic paracentesis should be performed in all patients with signs and symptoms (abdominal pain, fevers), encephalopathy, and renal failure and all hospitalized patients. The ideal approach is to drain a sample of ascites and inoculate the culture media at the bedside to maximize the yield of the cultures. ${ }^{3}$ Treatment and prophylaxis strategies for SBP are shown in Table 1.

\section{Hepatorenal Syndrome}

Hepatorenal syndrome is a serious functional renal dysfunction seen in patients with cirrhosis and ascites. The pathophysiology is complex and involves abnormal hemodynamics, splanchnic and systemic vasodilatation and renal vasoconstriction often triggered by a precipitating event. ${ }^{5}$ The diagnosis and management strategies are outlined in Table 2.

\section{Gastroesophageal Varices}

Gastroesophageal varices develop as a result of portal venous hypertension when the hepatic vein portal gradient is elevated ( $>6 \mathrm{~mm} \mathrm{Hg}$ ) but usually bleed when the pressure is elevated above $12 \mathrm{~mm} \mathrm{Hg}$. ${ }^{6}$ These collateral vessels

Abbreviations: CHE, covert hepatic encephalopathy; CT, computed tomography; EGD, esophago-gastroduodenoscopy; HCC, hepatocellular carcinoma; HE, hepatic encephalopathy; LT, liver transplantation; MHE, minimal hepatic encephalopathy; MRI, magnetic resonance imaging; NSBB, nonselective beta blockers; OHE, overt hepatic encephalopathy; PTH, portal hypertension.

From the Division of Gastroenterology and Hepatology, Mayo Clinic Arizona, Phoenix, AZ

Potential conflict of interest: Nothing to report.

View this article online at wileyonlinelibrary.com

(C) 2015 by the American Association for the Study of Liver Diseases

doi: $10.1002 /$ cld.462 
are present in almost 50\% patients with cirrhosis. Approximately $30 \%$ of patients with varices will bleed within the first year of diagnosis. The presence of varices correlates with the severity of the liver disease. The main risk factors for variceal hemorrhage are variceal size, advanced liver

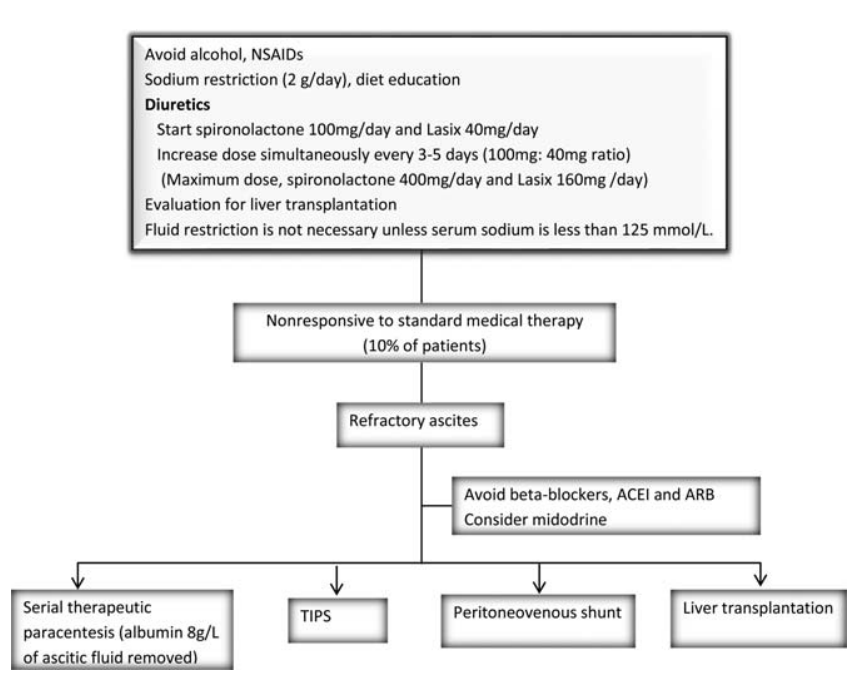

Figure 1 Management of ascites and therapeutic options for refractory ascites. Abbreviations: ACEI, angiotensin-converting enzyme inhibitor; ARB, angiotensin receptor blockers; NSAIDs, nonsteroidal anti-inflammatory drugs; TIPS, transjugular intrahepatic portosystemic shunt. disease (Child-Pugh class B or C), and presence of red wale marks at endoscopy. Esophago-gastroduodenoscopy (EGD) is the gold standard for the diagnosis of varices and should be performed in all patients once a diagnosis of cirrhosis has been established. ${ }^{7}$

Primary prophylaxis with nonselective beta blockers (NSBB) or endoscopic variceal ligation for those who are not eligible for NSBBs does improve survival in patients with esophageal varices. There appears to be no impact if NSBBs are started before varices are seen or when they are very small. ${ }^{8}$ Current consensus recommends NSBBs (propranolol, nadolol or carvedilol) or endoscopic variceal ligation for the primary prevention of first variceal bleed. ${ }^{6}$ However, nitrates, shunt surgery, and endoscopic sclerotherapy are not recommended for primary prophylaxis.

If no varices are identified on initial screening endoscopy, no therapy is recommended. Repeat EGD should be obtained after 3 years, earlier if the patient decompensates. ${ }^{9}$ The current management strategies after results of screening endoscopy in patients with cirrhosis are shown in Figure 2.

Other complications of cirrhosis are also of significant impact to the well-being of the patient with cirrhosis and will be listed below. These complications have more to do with preventive measures that are unique complications of cirrhosis and warrant careful attention.

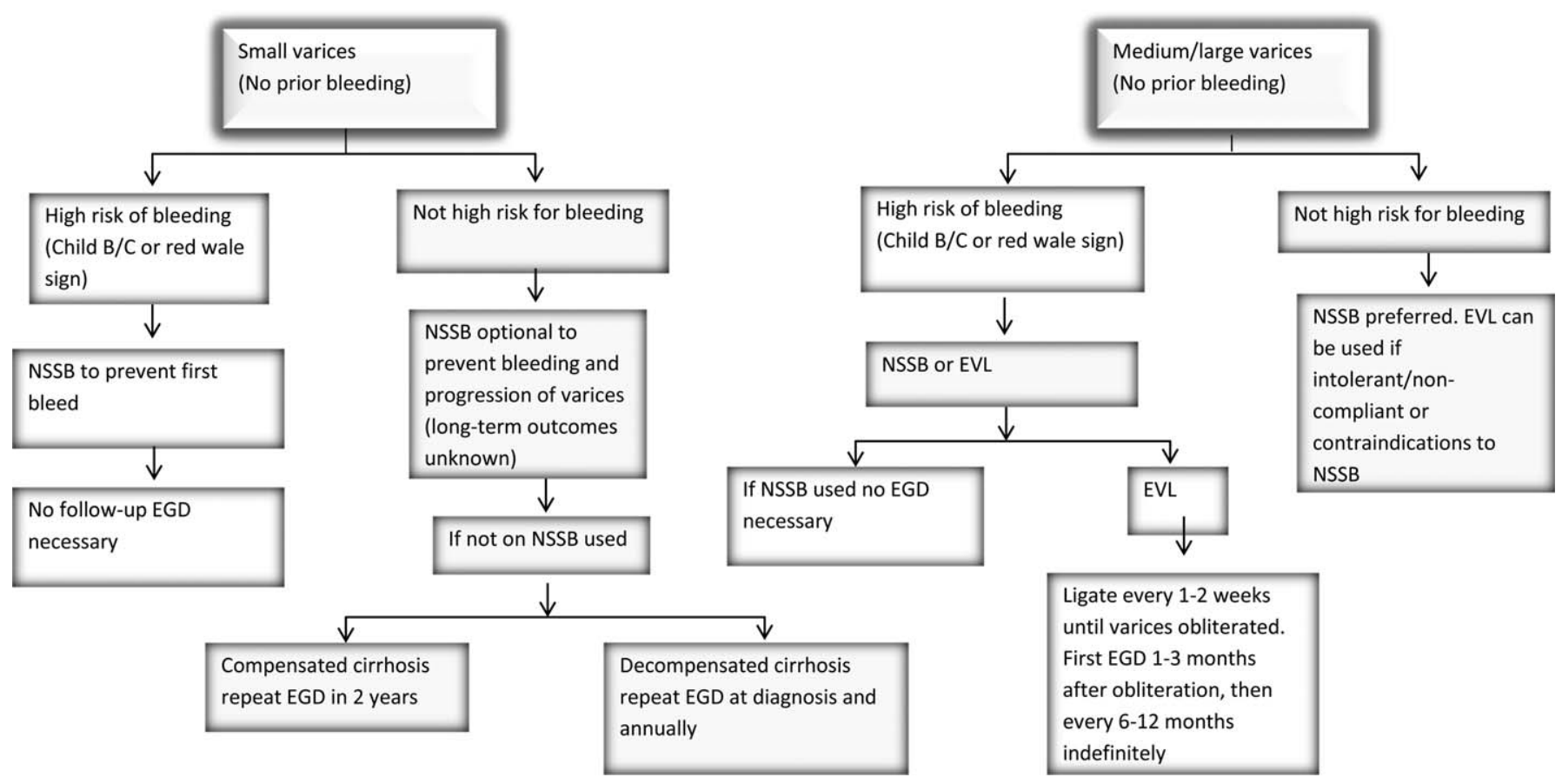

Figure 2 Management strategies after results of screening endoscopy in patients with cirrhosis. Abbreviations: EGD, esophago-gastroduodenoscopy; EVL, endoscopic variceal ligation; NSSB, nonselective beta blocker. 
TABLE 1 Diagnosis, Management, and Prophylaxis of Spontaneous Bacterial Peritonitis

\begin{tabular}{|c|c|}
\hline Diagnosis & $\begin{array}{l}\text { Ascitic fluid absolute polymorphonuclear leukocyte count is } \geq 250 \text { cells } / \mathrm{mm}^{3} \text { in the absence of surgically treat- } \\
\text { able intra-abdominal source of infection }\end{array}$ \\
\hline Risk factors & Prior episode of SBP, ascitic fluid total protein concentration $<1.0 \mathrm{~g} / \mathrm{dL}$, and variceal hemorrhage \\
\hline General measures & $\begin{array}{l}\text { Albumin infusion ( } 1.5 \mathrm{~g} / \mathrm{kg} \text { on day } 1 \text { and } 1 \mathrm{~g} / \mathrm{kg} \text { on day } 3 \text { ) if blood urea nitrogen }>30 \mathrm{mg} / \mathrm{dL} \text {, creatinine }>1 \mathrm{mg} / \\
\mathrm{dL} \text {, bilirubin }>4 \mathrm{mg} / \mathrm{dL}\end{array}$ \\
\hline Specific treatment & $\begin{array}{l}\text { Intravenous third-generation cephalosporin (cefotaxime } 2 \text { g every } 8 \text { hours or ceftriaxone } 2 \text { g every } 24 \text { hours) } \\
\text { Oral ofloxacin ( } 400 \text { mg twice per day) can be an alternative in hospitalized patients with no evidence of shock, } \\
\text { vomiting, hepatic encephalopathy (grade II), renal dysfunction (creatinine }>3 \mathrm{mg} / \mathrm{dL} \text { ) or previous exposure to } \\
\text { quinolone }\end{array}$ \\
\hline & Continue antibiotic therapy for 7 days \\
\hline Secondary prophylaxis & Long-term oral norfloxacin or trimethoprim/sulfamethasoxazole \\
\hline Primary prophylaxis & $\begin{array}{l}\text { In patients with cirrhosis and gastrointestinal hemorrhage, intravenous ceftriaxone or oral norfloxacin twice daily } \\
\text { should be given to prevent infections } \\
\text { Oral norfloxacin or trimethoprim/sulfamethasoxazole should be considered in cirrhosis patients with } 1 \text { ) ascitic } \\
\text { fluid total protein count }<1.5 \mathrm{~g} / \mathrm{dL} \text { along with renal dysfunction (creatinine } \geq 1.2 \mathrm{mg} / \mathrm{dL} \text {, blood urea nitrogen } \\
\quad \geq 25 \mathrm{mg} / \mathrm{dL} \text { or serum sodium } \leq 130 \text { ) or } 2 \text { ) liver failure (Child-Pugh score } \geq 9 \text { ) and serum bilirubin } \geq 3 \mathrm{mg} / \mathrm{dL}\end{array}$ \\
\hline
\end{tabular}

TABLE 2 Diagnosis and Management Strategy for Hepatorenal Syndrome

\begin{tabular}{|c|c|}
\hline International Ascites Club definition & $\begin{array}{l}\text { Cirrhosis with ascites } \\
\text { Serum creatinine }>133 \mu \mathrm{mol} / \mathrm{L}(1.5 \mathrm{mg} / \mathrm{dL}) \\
\text { No improvement of serum creatinine after at least } 2 \text { days with diuretic withdrawal and volume expansion with } \\
\quad \text { albumin } \\
\text { Absence of shock } \\
\text { No current or recent treatment with nephrotoxic drugs } \\
\text { Absence of parenchymal kidney disease }\end{array}$ \\
\hline \multicolumn{2}{|r|}{ 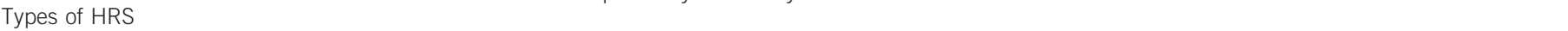 } \\
\hline Type 1 & $\begin{array}{l}\text { Rapid progressive renal failure with doubling of the initial serum creatinine concentrations to a level }>226 \\
\mathrm{mmol} / \mathrm{L}(2.5 \mathrm{mg} / \mathrm{dL}) \text { in }<2 \text { weeks }\end{array}$ \\
\hline Type 2 & $\begin{array}{l}\text { Moderate to slowly progressive renal failure with serum creatinine between } 1.5 \text { and } 2.5 \text { mg/dL (133-226 } \\
\mu \mathrm{mol} / \mathrm{L})\end{array}$ \\
\hline Precipitant factors & $\begin{array}{l}\text { Infection, bleeding, large volume paracentesis without albumin administration over diuresis, and acute hepatitis } \\
\text { secondary to alcohol or virus }\end{array}$ \\
\hline General management & Early identification and treatment of the precipitating event \\
\hline \multicolumn{2}{|l|}{ Specific management } \\
\hline Type 1 HRS & $\begin{array}{l}\text { Vasoconstrictors (terlipressin or norepinephrine) with albumin or midodrine (a selective } \alpha \text {-1 adrenergic agonist), } \\
\text { octreotide (a somatostatin analog), and albumin }\end{array}$ \\
\hline Type 2 HRS & Treatment options are typically directed toward the management of the refractory ascites \\
\hline Other options & $\begin{array}{l}\text { TIPS may be an alternative option in selected cases when medical therapy fails; renal replacement therapy may } \\
\text { be used as a bridging therapy until LT }\end{array}$ \\
\hline Definitive treatment & LT is the definitive treatment for patients with type 1 and 2 HRS \\
\hline
\end{tabular}

Abbreviations: HRS, hepatorenal syndrome; LT, liver transplantation; TIPS, transjugular intrahepatic portosystemic shunt.

\section{Hepatic Encephalopathy}

Hepatic encephalopathy (HE) is a debilitating complex neuropsychiatric complication characterized by motorsensory derangements ranging from subclinical cognitive impairment to overt coma, with many varied intervening mental status and neuromuscular changes in between. The prevalence of overt $\mathrm{HE}$ at the time of diagnosis of cirrhosis is around $11 \% .{ }^{10} \mathrm{HE}$ is classified into various subtypes based on type of underlying disease (type A, B, and C), severity of manifestations (minimal, grade I-IV), time course (episodic, recurrent and persistent), and precipitating factors. Patients with minimal HE (MHE) have mild cognitive and psychomotor impairment without overt clinical evidence of those changes. Covert HE (CHE) includes minimal and grade $1 \mathrm{HE}$.

The diagnosis of HE involves exclusion of other causes of brain dysfunction and identification of the precipitating causes (infections, gastrointestinal bleeding, diuretic overuse, electrolyte abnormalities, sedatives, and constipation). ${ }^{11}$ Overt HE (OHE) is diagnosed by clinical criteria, and testing for MHE and CHE encompass neurophysiological and psychometric tests. Diagnosing MHE and CHE has prognostic significance because it is associated with progression to OHE, poor quality of life, and high risk of accidents.

Treatment of OHE involves excluding nonhepatic causes of encephalopathy, identifying and treating the precipitating factors, supportive care, and initiating appropriate treatment. A summary of the available pharmacological therapies is given in Table 3. Educating patients and relatives regarding medication compliance, potential side effects, recognition of early signs of $\mathrm{HE}$, and measures to prevent recurrence is imperative. Treatment of MHE/CHE is not routinely recommended but can be considered in a selected patient population. 
TABLE 3 Summary of Therapies Used in the Management of Hepatic Encephalopathy

\begin{tabular}{|c|c|c|c|}
\hline Therapy & Uses & Dose & Adverse Effects \\
\hline Lactulose (nonabsorbable disaccharide) & $\begin{array}{l}\text { Treatment of episodic OHE and prevention of } \\
\text { recurrent episodes after the initial episode }\end{array}$ & 30--45 mL two to four times daily & $\begin{array}{l}\text { Aspiration, dehydration, } \\
\text { hypernatremia, and ileus }\end{array}$ \\
\hline Rifaximin (antibiotic) & $\begin{array}{l}\text { Add-on therapy to lactulose for treatment and } \\
\text { prevention of HE recurrence after the second } \\
\text { episode }\end{array}$ & 550 mg twice daily & Peripheral edema, nausea \\
\hline Metronidazole (antibiotic) & Alternative choice for treatment of $\mathrm{OHE}$ & $250 \mathrm{mg}-500 \mathrm{mg}$ three times daily & $\begin{array}{l}\text { Metallic taste, peripheral } \\
\text { neuropathy, ototoxicity }\end{array}$ \\
\hline Neomycin (antibiotic) & Alternative choice for treatment of $\mathrm{OHE}$ & $250 \mathrm{mg}$ two to four times daily & Ototoxicity Nephrotoxicity \\
\hline $\begin{array}{l}\text { Oral BCAAs (leucine, isoleucine, } \\
\text { and valine) }\end{array}$ & $\begin{array}{l}\text { Alternative or additional agent to treat patients } \\
\text { unresponsive to conventional therapy }\end{array}$ & & No known adverse effects \\
\hline LOLA & $\begin{array}{c}\text { Alternative or additional agent to treat patients } \\
\text { nonresponsive to conventional therapy }\end{array}$ & 20 g/day LOLA intravenous & Nausea/vomiting \\
\hline
\end{tabular}

Abbreviations: BCAAs, branched chain amino acids; LOLA, L-ornithine L-aspartate

\section{Hepatocellular Carcinoma Screening}

Screening for hepatocellular carcinoma (HCC) is recommended for all patients at high risk for developing HCC, including all patients with cirrhosis and patients who do not have cirrhosis but are hepatitis B carriers (Asian males $>40$ years of age, Asian females $>50$ years of age, Africans $>20$ years of age, and patients with a family history of HCC). ${ }^{12}$ Studies have shown a survival benefit with surveillance when HCC was diagnosed early and curative treatments were performed. ${ }^{13}$ Hence, surveillance for HCC is recommended with ultrasound (60\% sensitivity, 90\% specificity) every 6 months based on tumor growth rates. Alpha-fetoprotein is not a reliable measure for surveillance or diagnosis of HCC due to its lack of adequate sensitivity and specificity. With respect to candidates listed for LT, vigilant surveillance is necessary because tumor development will provide increased priority for LT. Furthermore, surveillance will help identify wait-list candidates who develop HCC that exceeds the guidelines for LT.

The diagnosis of HCC involves radiological examination, including four-phase multidetector computed tomography (CT), dynamic contrast-enhanced magnetic resonance imaging (MRI), or liver biopsy. The presence of arterial enhancement followed by washout in the portal and/or delayed phases on the CT or MR is diagnostic of HCC (sensitivity and specificity of $90 \%$ and $95 \%$, respectively). Liver biopsy is limited to lesions with no typical imaging characteristics or for those detected in noncirrhotic liver.

Nodules found on surveillance ultrasound should be managed further depending on the size of the lesion:

- Nodule $<1 \mathrm{~cm}$ found during surveillance should be followed by ultrasound examination every 3-6 months.

\section{References}

1. Garcia-Tsao G. Portal Hypertension. Curr Opin Gastroenterol 2006;22:254262.

2. Planas R, Montoliu S, Ballesté B, Rivera M, Miquel M, Masnou H, et al. Natural history of patients hospitalized for management of cirrhotic ascites. Clin Gastroenterol Hepatol 2006;4:1385-1394.
- Nodule $>1 \mathrm{~cm}$ : four-phase multidetector CT or dynamic MRI should be performed. If the appearances are typical of HCC, the lesion should be managed as HCC. If the findings are not diagnostic for HCC, a second imaging study should be performed, or the lesion should be biopsied.

\section{Immunization}

The Advisory Committee on Immunization Practices in the United States recommends hepatitis A, hepatitis B, 23valent pneumococcal polysaccharide vaccine (PPSV23), and inactivated influenza immunization for all patients with chronic liver disease. The immunogenicity for hepatitis $A$ and $B$ vaccination is reduced in patients with decompensated cirrhosis. ${ }^{14}$ Hence, vaccination is recommended early in the natural history of their liver disease. Patients should also receive standard immunizations such as diphtheria and tetanus booster immunizations every 10 years. Because cirrhosis patients are immunocompromised, inactivated/killed vaccines are preferred over live/attenuated vaccines.

\section{Malnutrition}

Daily protein intake $(1.2-1.5 \mathrm{~g} / \mathrm{kg} /$ day $)$ is recommended to avoid malnutrition, and oral branched chain amino acids can be considered for individuals intolerant of all protein. ${ }^{15}$ In severe malnutrition, initiation of enteral feeding improves nutritional status, reduces complications, and prolongs survival.

CORRESPONDENCE

Hugo E. Vargas, M.D., Division of Gastroenterology and Hepatology, Mayo Clinic Arizona, 5777 East Mayo Boulevard, Phoenix, AZ 85054. E-mail: vargas.hugo@mayo.edu

3. Runyon BA, AASLD. Introduction to the revised American Association for the Study of Liver Diseases Practice Guideline management of adult patients with ascites due to cirrhosis: update 2012. Hepatology 2013;57: 1651.

4. Bernardi M, Caraceni P, Navickis RJ, Wilkes MM. Albumin infusion in patients undergoing large-volume paracentesis: a meta-analysis of randomized trials. Hepatology 2012;55:1172-1118. 
5. Salerno F, Gerbes A, Ginès P, Wong F, Arroyo V. Diagnosis, prevention and treatment of hepatorenal syndrome in cirrhosis. Gut 2007;56:1310-1318.

6. Garcia-Tsao, G, Sanyal AJ, Grace N, Carey WD; Practice Guidelines Committee of American Association for Study of Liver Diseases; Practice Parameters Committee of the American College of Gastroenterology. Prevention and management of gastroesophageal varices and variceal hemorrhage in cirrhosis. Hepatology 2007;46:922-938.

7. North Italian Endoscopic Club for the Study and Treatment of Esophageal Varices. Prediction of the first variceal hemorrhage in patients with cirrhosis of the liver and esophageal varices. A prospective multicenter study. N Engl J Med 1988;319:983-989.

8. Groszmann RJ, Garcia-Tsao G, Bosch J, Grace ND, Burroughs AK, Planas R, et al. Beta-blockers to prevent gastroesophageal varices in patients with cirrhosis. N Engl J Med 2005;353:2254-2261.

9. Grace ND, Groszmann RJ, Garcia-Tsao G, Burroughs AK, Pagliaro L, Makuch RW, et al. Portal hypertension and variceal bleeding: an AASLD single topic symposium. Hepatology 1998;28:868-880
10. Jepsen P Ott P, Andersen PK, S\%orensen HT, Vilstrup H. Clinical course of alcoholic liver cirrhosis: a Danish population-based cohort study. Hepatology 2010;51:1675-1682

11. Fessel JN, Conn HO. An analysis of the causes and prevention of hepatic coma. Gastroenterology 1972;62:191.

12. Bruix J, Sherman M. Management of hepatocellular carcinoma: an update. Hepatology 2011;53:1020-1022.

13. Zhang BH, Yang BH, Tang ZY. Randomized controlled trial of screening for hepatocellular carcinoma. J Cancer Res Clin Oncol 2004; 130:417-422.

14. Leise MD, Talwalkar JA. Immunizations in chronic liver disease: what should be done and what is the evidence. Curr Gastroenterol Rep 2013; $15 \cdot 300$.

15. Cheung K, Lee SS, Raman M. Prevalence and mechanisms of malnutrition in patients with advanced liver disease, and nutrition management strategies. Clin Gastroenterol Hepatol 2012;10:117-125. 